DEPARTAMENTO DE HIGIENE. SACDF PEBLICA E BIOFSTATISTICA

Diretor: Prof. Dr. Adolpho Ribeiro Netto

ESTUDO EPIDEMIOLÓGICO EXPERIMENTAL DO EMPREGG DA TIODIFENILAMINA (FENOTIAZINA) NA PROFILAXIA DA ASCARIDIASE DAS GALINHAS *

(EXPERIMENTAL EPIDEMIOLOGICAL STUDY ON THE USE OF PHFNOTHIAZINE IN THE PROFILAXIS OF CHICKEN ASCARIASIS)

A. RIBBilRO NE:TTO

Cittedrático

\title{
CONSIDERACOES GERAIS
}

O último quartel do século passado teve a marcá-lo sucessivas descobertas que, firmando inicialmente o conceito parasitário de numerosas doenças, permitiram, em seguida, o estabelecimento de conceitos básicos da epidemiologia, esclarecendo as diferentes modalidades de transmissão dos agentes infectantes $\left({ }^{*}\right)$. Esta formidável tarefa de investigação estendeu-se ao século atual e, na rcalidade, ainda não está definitivamente concluída. De qualquer modo, porém, dispomos já de cabedal de conhecimentos que possibilitam o delineamento das grandes formas gerais de transmissão relacionadas e até mesmo subordinadas às caracteristicas dos parasitos, às vias pelas quais os agentes etiológicos abandonam o organismo infectado e às portas de entrada em novos hospedeiros.

De pronto, fica patente a existência de novas relações de dependência, desta vez entre as formas de transmissão e as medidas de profilaxia capazes de fornecer resultados satisfatórios em cada eventualidade. Para não sairmos do terreno das generalizações, basta invocar, como exemplo, a diversidade frisante observável entre as medidas de profilaxia que conduziram os sanitaristas a resultados espetacularmente brilhantes, em situações diversas; assim, de um lado, as medidas de saneamento, convenientemente aplicadas, permitiram o contrôle de infecções intestinais veiculadas por alimentos, enquanto de outro, as campanhas contra vetores biológicos possibilitaram a solução de problemas como os representados pela febre amarela urbana e a malária. Dificuldades muito maiores surgiam, porém, face aos agentes transmitidos por contágio, fazendo com que em casos como o da difteria ou da variola

(*) Tese apresentada para concorrer ao provimento cfetivo da 11 a $^{3}$ cadeira - Higicne. Saúde Púhlicá c Hiocestallística.

1*0) Neste cupitulo. Onde consideramos as medilus gerais de profiluxia aplicáveis aos

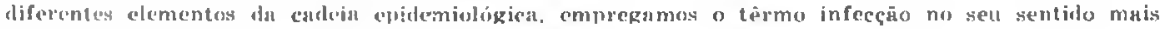

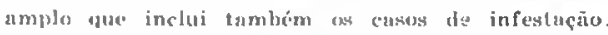


apenas a proteção aos suscetiveis, através da imunização, pudesse levar ao êxito procurado.

Não há como fugir, então, à necessidade de conhecimento amplo das características epidemiológicas de doenças cuja profilaxia se deseje realizar, para que se possam compreender as razões pəlas quais determinadas medidas serão, na prática, presumivelmente bem ou mal sucedidas.

Entre as formas de transmissão a serem consideradas, não só por abranger importante grupo de doenças, como face às peculiaridades envolvidas, é indispensável a da veiculação pelo solo de agentes que passam, obrigatória ou circunstancialmente, uma parte ou todo o prazo de sua permanência no meio exterior, dêle saindo para alcançar novo hospedeiro ativamente, através dos tegumentos, ou passivamente, seja por ingestão, seja ainda por soluções de continuidade dos mesmos tegumentos. Não se incluem aqui, portanto, casos de passagem pelo solo apenas acidental com a contaminação de alimentos, especialmente da água, o que transfere o problema para outra órbita.

Essencialmente, pois, para o mecanismo de transmissão em focc, a cadeia de fatos epidemiológicos abrangerá os seguintes elementos:

a) o agente infectante cuja passagem pelo solo é em alguns casos obrigatória para a realização de fase do ciclo evolutivo; em outros casos tal passagem ocorre circunstancialmente, exigindo do parasito a capacidade de resistir às condições adversas que o meio apresente;

b) a fonte de infecção da qual o agente infectante é eliminado por uma via que lhe permita alcançar o solo;

c) o suscetível que mantenha com o solo as relações necessárias para a concretização da infecção.

Dentre as doenças transmitidas segundo esta seqüiência epidemiológica avultam as parasitoses intestinais, de vasta importância, tanto na patologia humana, como, e principalmente, na veterinária. Dada essa importância, é natural que numerosos a variados recursos de cunho profilático tenham sido experimentados na luta contra tais parasitos.

Cabe aqui, pois, revisão sucinta das medidas preventivas, pondo em relêvo as razões condicionantes da relativa pobreza de resul- 
tados obtidos, testemunho da complexidade do problema e das dificuldades a solucionar.

Não se pode encontrar, provàvelmente, exemplo mais típico, para primeira apresentação do problema, do que o representado pela ancilostomose humana, doença largamente difundida em todo o mundo e de extraordinário scgnificado, quer do ponto de vista da patologia, quer pelos seus aspectos econômicos e sociais. Em nosso país, ela constitui um dos mais graves problemas sanitários, desafiando esforços desenvolvidos já de longa data.

No terreno da veterinária são inumeráveis as parasitoses dessa natureza, com significado econômico transcendental: a estrongilose eqüina; as dictiocauloses de bovinos e ovinos; as hemoncoses dos carneiros e bovinos; a ascaridíase dos suinos, como também as dos cães e aves, são apenas algumas dentre as muitas a citar.

Vejamos, pois, quais as medidas de profilaxia a considerar, prccurando apresentá-las em função do elemento da cadeia epidemiológica em que precipuamente devam atuar; analisemos, em primeiro lugar, as medidas de profilaxia referentes à fonte de infecçãc.

De início, cumpre discutir a destruição dessa fonte por meio do sacrifício dos infectados. Òbviamente inaplicável para o homem, tal prática é exequível para outros animais e numerosos são os casos onde o seu emprêgo é justificável ou mesmo recomendável, não obstante as consideraçōes de ordem econômica implicadas. Entretanto, para o problema em exame, a medida é previsívelmente de pouca valia, porquanto com ela não suprimimos o agente infectante, já presente no solo, e que irá, em curto tempo restabelecer a infecção que se pretendera extinguir na população.

Medida menos drástica mas com os mesmos objetivos, é a que visa a esterilização medicamentosa das fontes de infecção; além da insuficiência atribuivel à mesma razão apontada para a medida anterior, cabe ainda a discussão relativa à existência de drogas que satisfaçam os requisitos indispensáveis de eficiência, no tocante ao agente, e de tolerabilidade, no respeitante ao hospedeiro.

Quanto à ancilostomose humana, os chamados tratamentos em massa de populações parasitadas têm sido advogados por numerosos investigadores e largamente postos em prova repetidas vêzes. É bem compreensivel o descrédito em que de forma geral cairam, frente aos decepcionantes resultados obtidos, imputáveis não tanto 
à inoperância dos agentes medicamentosos usados, quanto à manutenção da contaminação do solo e às condições econômico-sociais e educacionais das populações tratadas.

No âmbito da veterinária, êste tipo de profilaxia vem merecendo, também, largo emprêgo, administrando-se aos animais doentes as mais diversas drogas, com o fito de promover a eliminação dos parasitos e de obter a cura da doença. Os resultados, anàlogamente, têm ficado muito aquém da espectativa e os motivos se enquadram, sem dúvida, entre os já apontados.

Restaria ainda a possibilidade, pelo menos teórica, do isolamento das fontes de infecção, procedimento tão importante na profilaxia de certas doenças. Entretanto, no problema $\mathrm{em}$ foco a realização prática da medida está fora de cogitação, pois as parasitoses de maior significado são justamente as que atingem grande parte das coletividades, não se limitando a incidências mais ou menos esporádicas onde a fonte de infecção se transforma numa exceção dentro do conjunto populacional.

Pode admitir-se, portanto, de forma geral, que as medidas clássicas de profilaxia, através das quais se visa a fonte de infecção, não apresentam condições de êxito previsivelmente favorável.

Passemos, então, a analisar as medidas utilizáveis no sentido de quebrar a cadeia de transmissão durante a permanência do agente no meio exterior, ou sejam, as aplicáveis à via de transmissão, no caso o solo. De pronto, pode considerar-se a que ocupa, naturalmente, o primeiro lugar na sucessão de eventos, por visar impedir venha o agente infectante, uma vez eliminado do hospedeiro, a contaminar o solo em condições compatíveis com sua evolução ou simples sobrevivência. Para tanto, é necessário estabelecer qual, entre as possiveis vias de eliminação, representa o principal papel em problemas desta natureza.

Não cabem dúvidas quanto à primazia atribuivel à eliminação por excretos fecais e urinários, especialmente com relação aos primeiros, não havendo mesmo necessidade de se examinarem outras vias.

Diante disto, abre-se para os sanitaristas, em certos casos, possibilidade de atuação altamente eficiente, fundada na destinação adequada dos excretos, garantindo a não contaminação do solo.

Isto é particularmente verdadeiro quando se trata de excretos humanos, pois dispomos de múltiplos recursos, desde os elaborados 
sistemas para coleta e tratamento de excretos, até a rudimentar fossa negra. Teoricamente, admite-se tal medida como suficiente para promover a erradicação das endemias causadas por parasitos intestinais humanos, que se enquadrem no esquema epidemiológico em aprêço. Na prática, entretanto, óbices muitas vêzes intransponíveis tem-se oposto à sua realização; a ignorância, a carência de recursos, os hábitos de vida secularmente arraigados, fazem com que a contaminação do solo se processe contínua e pesadamente. Eis como se explica que a ancilostomose continue a representar ainda um dos mais terríveis solapadores da saúde das nossas populações rurais.

Já no caso de outras espécies animais, decresce, claramente, a possibilidade de utilização dêste tipo de profilaxia, apenas ernpregável em casos determinados, constituindo, a propósito, o piso de tela de galinheiros, exemplo típico. Destarte, em veterinária, as perspectivas de solução de problemas por esta forma são de pequena monta.

Uma vez verificada a contaminação do solo, pouco há a fazer-se; ao contrário do que acontece em se tratando da transmissão por alimentos, onde as práticas de desinfecção do veículo são realizáveis com alta eficiência, vemo-nos frente a dificuldades quase invenciveis para a desinfecção do solo. Ainda em circunstâncias particulares é possivel obter resultados satisfatórios utilizando recursos como o da inundação de terrenos, desde que, assim, se criem condições desfavoráveis à vida do agente infectante. Òbviamente, em poucas situações tal medida será exequível. Algumas regiões afortunadas, submetidas a invernos rigorosos, encontram no congelamento hibernal do solo aliado por vêzes altamente eficaz para efetivar a destruição natural de agentes patogênicos vulneráveis ao frio. Infelizmente, isto não ocorre na quase totalidade do território brasileiro.

Medidas como a da rotação de pastos, visando aguardar que as formas infectantes, presentes no solo, desapareçam por meios naturais, não só se revelam ineficientes em alguns casos, como requerem áreas nem sempre disponíveis.

As técnicas de desinfecção por meios químicos ou mecânicos ficam limitadas, logicamente, a pequenas extensões de terreno e mostram-se, portanto, incapazes de se constituirem em solução genérica. 
Destas considerações ressalta o fato de que pouco devemos esperar das medidas de profilaxia referentes à época de permanência do agente no meio exterior, maxime no referente aos problemas de vetcrinária.

Não ficaram esgotados, entretanto, os recursos possiveis. Resta ainda pensar na protecão do suscetivel contra o agente infectante. Mais uma vez observamos a nítida situação de inferioridade $\mathrm{cm}$ que se encontra o sanitarista, ao lidar com êste tipo epidemiológico, por não poder valer-se de meios disponiveis em outras situações.

De fato, não raramente a falência das medidas já apreciadas é remediada, de modo decisivo, pela adoção de técnicas de imunização passiva e, principalmente, ativa dos suscetíveis. Assim se resolvem problemas como os da varíola, da difteria, da poliomielite, da raiva, da aftosa, da brucelose, da cinomose, do tétano e tantos mais. Em contraposição, os conhecimentos fundamentais, no campo da imunidade, quando se trate de helmintos, não encontram ainda possibilidades de utilização prática.

Privados desta arma, dispomos somente de medidas de caráter particular e, por vêzes, insuficientes. No caso do homem, por exemplo, a proteção contra a penetração de larvas de ancilostomídeos, por meio de calçados, esbarra nos mesmos problemas mencionados anteriormente. $O$ aproveitamento do acréscimo da resistência a certas parasitoses, verificável com o aumento da idade do hospedeiro, por meio da segregação dos indivíduos jovens, para livrá-los da infecção nessa fase da vida, nem scmpre pode ser efetivado, pelas dificuldades de realização que, obviamente, apresenta.

Métodos outros de profilaxia, como os destinados a reduzir os riscos de infecção decorrentes da aglomeração, ficam naturalmente sujeitos às contingências de ordem material, especialmente econômicas.

Com estas últimas medidas esgotam-se os procedimentos usualmente adotados para a luta contra as doenças transmitidas pelo solo, com o mecanismo estudado. Evidentemente, a conclusão a que se chega é desalentadora, tão desalentadora que cria no espírito do sanitarista, a consciência da necessidade de pesquisas que possam, eventualmente, propiciar a obtenção de novos recursos profiláticos pertinentes a qualquer dos setores de atuação, capazes de trazer alguma modificação favorável, pelo menos no âmbito de certos problemas compreendidos no conjunto. 
Tendo em mente estas idéias, tivemos nossa atenção atraída pelos achados de ROCHA 1. : investigando os mecanismos de ação da tiodifenilamina (fenotiazina), êste autor demonstrou o poder da droga de inibir a ovoposição de fêmeas adultas de Ascaridia galli (Schrank, 1788) presentes no intestino de pintos, como também o de impedir o desenvolvimento embrionário de ovos dêsse helminto; acenou mais o mesmo pesquisador para a possibilidade, evidenciada em provas preliminares, de que idênticos fenômenos viessem a se dar em outras espécies de helmintos; patenteou, ainda, certa atividade vermífuga da droga contra as formas adultas do parasito, atividade esta insuficiente para promover a eliminação total.

Tais verificações assumem extraordinária importância porque trouxeram explicação para dados constantes na literatura, que mostravam discrepância entre os resultados referentes à pesquisa de ovos nas fezes e de parasitos adultos no intestino de animais sacrificados. Fatos de tal natureza, aparentemente paradoxais, são relativamente freqüentes na vasta bibliografia acumulada sôbre a fenotiazina, nos vinte anos decorridos desde o trabalho inicial de HARWOOD, JERSTAD \& SWANSON". Para citar apenas um exemplo, parece-nos suficientemente elucidativo o trabalho conduzido na Estação Experimental de Kentucky, por período superior a quatro anos. Durante êste tempo, alguns eqüideos receberam, continuamente, pequena dose diária de fenotiazina, suficiente, todavia, para manter as fezes pràticamente livres de ovos de nematóids durante todo o decurso da prova, resultado que foi motivo de sucessivas publicações de TODD e col. ${ }^{4} \cdots " \cdots$. Findo êste período, DRUDGE e col. " " sacrificaram os animais de experiência e encontraram, nos submetidos ao tratamento, não sòmente número surpreendente de nematóides, mas, também a presença de tôdas as nove espécies identificadas nos testemunhos. Êsses trabalhos de DRUDGE e col. tornam menos fundado o entusiasmo de seus predecessores, quanto à suposta proteção direta dos hospedeiros expostos às formas infectantes de nematóides, pela simples administração continuada de fenotiazina, em pequenas doses; por outro lado, êsses mesmos trabalhos puseram em relêvo fato fundamental: sob a influência da droga, os vermes existentes nos hospedeiros deixaram de reproduzir as formas infectantes iniciais.

A experimentação até agora realizada com a fenotiazina, com sentido profilático, enquadra-se, em sua quase totalidade, no tipo 
de atuação já discutido, que visa a cura da fonte de infecção, por destruição do agente infectante, mediante medicamento.

Resolvemos, portanto, utilizar no campo da profilaxia as verificações experimentais de ROCHA ${ }^{\prime}$ : : a ação impediente da fenotiazina sôbre a evolução embrionária de ovos de $\mathbf{\Lambda}$. galli e outros nematóides poderia constituir-se em forma de luta contra o parasito durante a permanência no solo; além disto, esta mesma ação e mais a atividade inibidora sôbre a ovoposição, permitem entrever-se uma nova modalidade de profilaxia medicamentosa, em que se visa não a destruição do agente infectante, mas, o impedimento da contaminação do solo.

Evidentemente, se fôsse atingível êste objetivo, ter-se-ia conseguido atuação em tudo semelhante, mutatis mutandis, à que obtêm os sanitaristas em populações humanas, quando alcançam uma efetivação perfeita de medidas relativas à destinação e tratamento dos excretos.

Nosso problema consistiria, então, fundamentalmente, em realizar investigação no terreno da epidemiologia experimental, com o fito de verificar se os achados de laboratório corresponderiam os resultados que, teòricamente, seria lícito esperar no campo da profilaxia.

Para ensaio pioneiro, pareceu-nos aconselhável trabalhar com o mesmo agente infectante e com o mesmo hospedeiro utilizados nas pesquisas de ROCHA ${ }^{1,2}$.

Como ó óbvio, a generalização dos resultados assim obtidos exigirá outras investigaçōes; mas, em se confirmando a espectativa, novas e promissoras possibilidades ficarão abertas, no terreno até então sáfaro da profilaxia de doenças subordinadas ao esquema epidemiológico discutido.

Para o planejamento desta tese contamos com a colaboração dos Professôres Pedro Egydio de Oliveira Carvalho, Walter Sidney Pereira Leser, Dorival da Fonseca Ribeiro, e ainda, com a do Dr. Uriel Franco Rocha e da Dra. Elza Salvatori Berquó, que juntamente com o Professor Francisco Antonio Cardoso, participaram também da discussão dos resultados. A análise estatística foi realizada pelo Professor Pedro Egydio de Oliveira Carvalho e pela Dr. Elza Salvatore Berquó.

A todos êstes mestres consignamos nossa profunda gratidão. 


\section{EXPERIMENTAÇÃO}

Fundamentalmente, nossa experimentação objetivou pôr em prova a hipótese de nulidade, segundo a qual a fenotiazina não exerce qualquer ação inibidora, utilizável para fins profiláticos, sôbre a postura ou sôbre o desenvolvimento embrionário de ovos de A. galli.

Suposta verdadeira esta hipótese, seria de se esperar, quer se adicionasse ou não fenotiazina aos solos, quer se tratassem ou não com a droga pintos seguramente parasitados que os ocupavam, fôsse o grau de contaminação de tais solos sempre o mesmo.

A verificação da legitimidade desta decorrência da hipótese de nulidade impunha a necessidade de averiguar, numa segunda etapa, se outros pintos — não parasitados — colocados naqueles diferentes solos, viriam a ser parasitados com a mesma intensidade.

Diante do exposto, a experiência foi planejada comportando duas fases: uma, preparatória, na qual se processasse a eventual contaminação dos solos nas várias condições previstas; outra, final, em que pelo estudo da infestação de um segundo grupo de pintos colocados naqueles solos, procurássemos elementos para decidir pela aceitação ou rejeição da hipótese de nulidade. Adotamos como nivel de rejeição o valor 0,05 .

\section{FASE PREPARATORIA}

1. Agente infestante - Escolhido o A. galli, foi necessário garantir uniformidade do material infestante a utilizar em todos os lotes de pintos. Para tanto, extraimos os ovos de fêmeas retiradas de intestinos de galinhas abatidas em matadouro, cultivando-os pela técnica de RIEDEL ", modificada por HANSEN e col. ".

Iniciou-se a cultura quatorze dias anteriormente à data prevista para a infestação experimental, prazo êste, segundo a maioria dos autores, adequado para o desenvolvimento embrionário completo dos ovos de A. galli, em estufa a $28^{\circ} \mathrm{C}$.

Para a infestação, fêz-se suspensão de ovos e, enquanto o auxiliar continha a ave com o bico aberto, o operador, valendo-se de pipeta, administrativa uma gôta do material infestante. Antes da infestação de cada ave, homogeneizava-se a suspensão de ovos, por aspiração e expiração repetidas, com a própria pipeta. 
Estimaram-se os parämetros da distribuição casual do numero de ovos larvados com gôta desta suspensão, realizando-se cinco determinaçōes, que conduziram à média de 314 ovos por gôta, com um desvio padrão populacional igual a 6,1 .

2. Hospedeiro - O primeiro problema considerado consistiu em admitir-se, ou não, cue os animais de experiência apresentassem variações quanto a certos fatôres supostos relevantes, como por exemplo: raça, idade, sexo. Naturalmente, em caso afirmativo, dever-se-ia desde logo planejar um meio do balancear êstes fatóres de variação nos lotes a serem submetidos aos diversos tratamentos.

Razões de ordem teórica, como também, e principalmente. de natureza prática, fizeram, entretanto, com que não permitíssemos as referidas variações. Dentre elas destacamos: a) a impossibilidade de assegurar que os animais, particularmente os menos jovens, estivessem livres de infestação quando do início da experiência; b) o aumento, com a idade, da resistência ao parasitismo; c) as dificuldades que surgiriam na ocasião do tratamento, condicionando o emprêgo de doses diversas da droga; d) o problema da coabitação de aves de idades várias, conduzindo em ambiente confinado a maior mortalidade das aves de menor porte.

Nestas condições, servimo-nos, para a realização desta parte preparatória, de 75 pintos da raça Leghorn $(*)$, nascidos em incubadoras, diagnosticados como machos e recebidos com um dia de idade. Estas aves foram instaladas em criadeiras limpas e desinfectadas, providas de piso de tela metálica, aí permanecendo em lote único até o momento de transportá-las para os solos.

Infestamos os pintos com vinte dias de idade e alimentamo-los durante todo o decorrer da experiência com razção balanceada. (**)

3. Contrôle da infestação - A seqüência experimental exigia a comprovação do êxito da infestação. Não sendo possível o sacrifício dos pintos antes da sua utilização para a contaminação dos

\footnotetext{
(*) Dondos mola Coxperativa Agrícola de Cotisn.

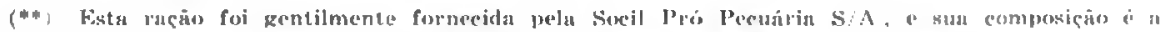

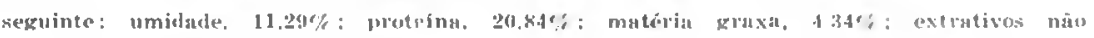
azotados. 53.29\%: matéria fibrosa, $4.62 \%$ : cinzas. $5.60 \%$ : crilcio. $1.41 \%:$ fósforo. $0.65 \%$; vitamina A. 6.000.000 U.I. po: tone'sula: vitamina D, 1.200 .000 I. 1. por to-

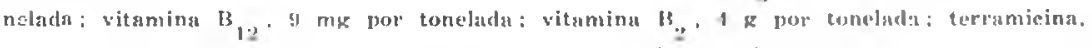
$11 \mathrm{~g}$ yor toneluda: truges de manganös, iódo. ferro. cobre e cobalto.
} 
solos, verificamos, pela técnica de Willis, tal como descrita por PESSOA ${ }^{12}$ a presença de ovos nas fazes, para aquilater a eficiência da infestação.

A partir do $25 .^{\circ}$ dia da infestação, passamos a recolher diàriamente os excrementos de todo o grupo, tomando, após homogeneização, amostra dêste material, para pesquisa de ovos de $\boldsymbol{\Lambda}$. galli.

O exame de fezes revelou-se positivo no $29 .{ }^{\circ}$ dia, a contar do da infestação; daí por diante foram realizadas, também diàriamente, contagens de ovos nas fezes pelo método de Stoll, modificado por PESSOA ${ }^{12}$.

Vê-se no quadro I que o número de ovos por grama de fezes aumentou progressivamente até o $35 .^{\circ}$ dia, época em que, segundo TUGWELL \& ACKERT ${ }^{1: 3}$ e ROCHA ', deve estar terminada a fase tecidual do ciclo do $\boldsymbol{\Lambda}$. galli.

QUADRO I

Nümero de ovos de 1. galli, presentes por grama de fezes, entre o $29 . "$ e o 36. dias da infestação experimental

\begin{tabular}{c|c}
\hline Diàs após a infestação & Número de ovos \\
\hline \hline 29 & - \\
30 & 200 \\
31 & 600 \\
32 & 800 \\
33 & 900 \\
34 & 1000 \\
35 & 1400 \\
36 & 1400 \\
\hline
\end{tabular}

4. Agente medicamentoso - Empregamos fenotiazina, tipo comercial, em comprimidos e em pó. Os comprimidos foram reduzidos mecânicamente a grânulos, sendo preparadas, por pesada simples em balança analítica, 540 doses de $250 \mathrm{mg}$ e outras tantas de $125 \mathrm{mg}$. As doses foram conservadas, separadamente, em pequenos tubos de ensaio. O produto em pó foi dividido em três porções: duas de $135 \mathrm{~g}$ e outra de $67,5 \mathrm{~g}$. 
5. Tratamentos - Para apreciação adequada do problema decidimos estudar o efeito da fenotiazina, ministrada ao animal ou adicionada ao solo; no primeiro caso dois aspectos mereceram consideração: um, em que se visava a exatidão da dosagem; outro, onde se levava em aprêço a praticabilidade da administração. Então, ou a droga seria ministrada através de sonda ou incorporada à ração. Além disso, urgia estudar eventual interação dos efeitos da droga quando ministrada ao animal e quando adicionada ao solo. Finalmente, como é natural em planejamento dêsse tipo, impunha-se a existência de testemunhos.

Compreende-se, assim tivéssemos organizado cinco lotes que designaremos doravante, como é habitual, pol tratamentos simbolizados pelas primeiras letras maiúsculas do alfabeto:

A) testemunho;

B) fenotiazina granulada, por via oral, administrada com auxílio de sonda;

C) fenotiazina em pó, adicionada ao solo;

D) fenotiazina em pó, adicionada ao solo, e granulada, admi nistrada per os, através de sonda;

E) fenotiazina em pó, por via oral, misturada à ração.

Algumas particularidades relativas aos quatro últimos tratamentos serão expostas a seguir.

Tratamento $\mathbf{B}$ (fenotiazina granulada, por via oral, administrada com auxílio de sonda) - A ministração da droga por sonda buscava assegurar a ingestão de dose conhecida. Por outro lado, evitava-se também confundir a ação atribuível à droga, fornecida por via oral, com a imputável à adição da substância ao solo. De fato, quando se incorpora à ração o agente medicamentoso, é pràticamente inevitável seja êle lançado ao solo durante a alimentação dos pintos.

Para a administração da fenotiazina usamos sonda com funil adaptado a uma das pontas, sendo a extremidade livre introduzida, através da abertura oral, no esôfago da ave, imobilizada por auxiliar. A dose de fenotiazina, contida em tubo de ensaio, era então vertida no funil e sua passagem pela sonda assegurada, mediante introdução de estilete metálico adequado; facilitava-se tal passagem pelo emprêgo de fenotiazina granulada, em lugar da pul- 
verizada, que tenderia a aderir às paredes da sonda, viciando destarte a dose, fixada em $500 \mathrm{mg}$ diários per capita.

Para garantir menor variação horária da concentracão da droga no intestino, fazia-se sua administração em duas parcelas diárias iguais: uma pela manhã e outra à tarde.

Tratamento $\mathbf{C}$ (fenotiazina em pó, adicionada ao solo) - Pretendeu-se no caso estudar a ação da fenotiazina, no tocante ao desenvolvimento embrionário dos ovos do A. galli que chegassem ao solo.

Preferimos valer-nos da fenotiazina em pó, para dispersá-la mais uniformemente. Servimo-nos de quantidade idêntica ao total estabelecido para as aves submetidas ao tratamento $\mathbf{B}$.

Depositamos a substância no solo de uma só vez, por meio de peneira de malhas finas $(0,42 \mathrm{~mm})$, com o fim de obter, tanto quanto possível, distribuição homogênea do pó.

Tratamento D (fenotiazina $\mathrm{cm}$ pó, adicionada ao solo, e granulada, administrada per os) - Como se viu, êste tratamento visou fundamentalmente revelar eventual interação dos tratamentos $\mathrm{B}$ e C.

Obedecendo à norma de utilizar sempre a mesma quantidade total de fenotiazina para os diferentes tratamentos, desta feita destinou-se metade da dose ao solo, segundo a técnica descrita no item anterior, e ministrou-se o restantc por via oral, como no tratamento $\mathrm{B}$.

Tratamento $\mathbf{E}$ (fenotiazina em pó, por via oral, misturada à ração) - Como se apontou, a administração do medicamento através de sonda apresenta óbvios inconvenientes. Decidimos, porisso, investigar o resultado da adição da droga à ração, embora cientes das desvantagens que tal veículo oferece com relação ao rigor experimental. Quando, entretanto, os dados fornecidos pelo tratamento $B$ indicassem atividade da fenotiazina no sentido previsto, os obtidos pelo tratamento $\mathrm{E}$ viriam trazer informes complementares sôbre as condições em que poderia ministrar-se a substância, na prática.

Sendo de $100 \mathrm{~g}$, segundo EWING ${ }^{11}$, o consumo médio diário de ração por pinto com idade aproximada de dois meses, e mantendo ainda o critério de constância da dose total empregada em cada tratamento, ajuntamos $500 \mathrm{mg}$ da droga a cada $100 \mathrm{~g}$ de alimento. 
6. Início dos tratamentos - Para fixar-se o inicio dos tratamentos deveríamos levar em conta o prazo requerido para que o medicamento exercesse, no grau máximo, sua atividade na direção antevista, de acôrdo com as circunstâncias de cada caso. Assim, no tratamento $\mathrm{C}$, a ação seria imediata, pois, procurava-se impedir, no solo, a evolução dos ovos de $\boldsymbol{\Lambda}$. galli.

Administrando-se a substância por via oral era necessário aguardar a eventual interrupção da ovoposição, para só depois serem os animais colocados em contacto com o solo cuja contaminação se pretendia evitar. Ora, tendo ROCHA - demonstrado não mais existirem ovos de A galli. nas fezes de pintos comprovadamente parasitados, 72 horas após a instituicão da terapêutica pela tenotiazina, as aves sujeitas ao tratamento oral apenas foram para o solo após o terceiro dia da medicacão. prolongada por mais quinze dias, ou scja por todo o tempo que nêle permaneceram.

7. Constituição dos lotes - O total de aves submetidas a qualquer dos tratamentos enumerados reccbeu a designação de lote; aos diferentes lotes atribuiram-se as mesmas letras simbolizadoras dos tratamentos aplicados.

Levando cm consideração a área dos pinteiros e, tendo em mira a desejada contaminação dos solos, estabelecemos o número de quinze aves por lote.

Os pintos foram alotados por casualização: começamos por sortear, utilizando a tabela de números casuais e a técnica de FISHER \& YATES ${ }^{15}$, três entre todos os possiveis quadrados latinos de lado cinco; a seguir, com a mesma técnica de sorteio, estabelecemos a correspondência entre as letras dos quadrados e as dos nossos tratamentos. Isto pôsto, realizou-se a alotação, mediante distribuição dos animais primitivamente infestados, pelos cinco tratamentos, em obediência às linhas dos três quadrados latinos. Assim, tomadas uma a uma, a reparticão das aves pelos tratamentos ía sendo ditada pela verificação, nos quadrados latinos, da letra que lhes cabia.

8. Preparo dos solos - A terra que constituiu o piso dos pinteiros foi retirada de terrenos da Faculdade de Medicina Veterinária, sendo inicialmente passada através de peneira de malhas grossas $(8 \mathrm{~mm})$ e em seguida colocada em baldes, para ser aquecida em mufla a $400^{\circ} \mathrm{C}$, durante trinta minutos, condiçōes exigidas para que a massa de terra situada no centro do balde atingisse 
$100^{\circ} \mathrm{C}$, conforme comprováramos mediante estudo preliminar. Com isto assegurávamos, largamente, a destruição de ovos de parasitos porventura presentes no material. A seguir, transportou-se a terra para cinco pinteiros idênticos, com soalho de madeira, medindo 2 metros por 1 e com rebordo também de madeira, com cêrca de 10 $\mathrm{cm}$ de altura.

Foram necessários cêrca de $500 \mathrm{Kg}$ de terra, repartidos por igual entre os cinco pinteiros, a fim de se conseguir camada de aproximadamente cinco centímetros de espessura. Depois de destinados a cada um dos lotes, foram os pinteiros colocados, por sorteio, em posiçōes prefixadas, em local fechado.

Antes da transferência das aves para a terra foi esta umedecida, regando-se cada pinteiro com mais ou menos 10 litros de água.

9. Permanência nos solos - Distribuidos os lotes pelos pintciros, os animais ai permaneceram durante quinze dias, continuando a receber a raçāo já mencionada.

Com esta permanência ficava assegurado prazo suficientemente longo de contaminação dos solos; além disto, conhecendc-se o tempo requerido para o desenvolvimento embrionário completo de ovos de A. galli, da ordem de quinze dias nas circunstâncias da cxperiência, podia esperar-se que outras aves, colocadas sôbre os mesmos solos logo em seguida, lá encontrassem ovos infestantes e também oves cuja maturação iria completar-se nos dias subseqüientes.

Tinhamos prèviamente estabelecido o seguinte critério: caso algum pinto viesse a morrer num dos lotes, seria também eliminado, por sorteio, um exemplar de cada um dos restantes. Esta prática não chegou a ser exigida, porquanto tôdas as aves sobreviveram; mas seu fundamentc residia no fato da contaminação do solo depender, ao menos em parte, do total de animais parasitados que nêle vivam.

10. Contrôle da fase preparatória - A verificação da existência de ovos de A. galli nas fezes dos pintos constituia, por si só, segurança do êxito da infestação, experimental, tendo-se em vista os achados de ROCHA ", relativamente à incapacidade da fenotiazina de eliminar a totalidade dos parasitos, era de prever-se que os animais submetidos ao tratamento por via oral (lotes B. D, E) não tivessem ficado livres da infestação até ao término da sua participação na experiência. Entretanto, visando uma comprovação dêste fato, seguramente de importância básica na interpretação dos 
resultados da fase final da experiência, procedeu-se à contagem dos vermes da luz intestinal dos pintos, sacrificados imediatamente depois de afastados dos solos. Foi utilizada a técnica de ACKERT $\&$ NOLF ${ }^{11}$, que consiste em retirar os helmintos do trato intestinal por fluxo hidráulico.

Os resultados obtidos constam do quadro II.

QUADRO II

Número de vermes encontrados na luz intestinal de cada um dos pintos. em cada um dos lotes

\begin{tabular}{|c|c|c|c|c|c|}
\hline & \multicolumn{5}{|c|}{ Lotes } \\
\hline & A & B & $\mathrm{C}$ & $\mathrm{D}$ & $\mathrm{E}$ \\
\hline & $\begin{array}{r}1 \\
1 \\
3 \\
4 \\
4 \\
4 \\
7 \\
8 \\
8 \\
8 \\
12 \\
12 \\
13 \\
14 \\
22\end{array}$ & $\begin{array}{l}0 \\
0 \\
0 \\
0 \\
0 \\
0 \\
0 \\
0 \\
1 \\
1 \\
2 \\
2 \\
3 \\
3 \\
6\end{array}$ & $\begin{array}{r}0 \\
1 \\
2 \\
3 \\
3 \\
4 \\
5 \\
5 \\
7 \\
9 \\
10 \\
10 \\
13 \\
18 \\
25\end{array}$ & $\begin{array}{r}0 \\
0 \\
2 \\
2 \\
3 \\
3 \\
4 \\
5 \\
6 \\
6 \\
7 \\
12 \\
15 \\
15 \\
18\end{array}$ & $\begin{array}{r}0 \\
0 \\
0 \\
2 \\
2 \\
2 \\
3 \\
3 \\
4 \\
5 \\
7 \\
8 \\
11 \\
13 \\
15\end{array}$ \\
\hline 'Total $\ldots \ldots \ldots \ldots$ & $121^{\circ}$ & 18 & 115 & 98 & 75 \\
\hline N." médio & 8,1 & 1,2 & 7,7 & 6,5 & 5,0 \\
\hline N." mediano ... & 8 & 0 & 5 & 5 & 3 \\
\hline N." de pintos sem vermes .. & 0 & 8 & 1 & 2 & 3 \\
\hline Desvio padrão ............ & 5.5 & 1,7 & 6,6 & 5,6 & 4,6 \\
\hline $\begin{array}{l}\text { Cocficiente de variabilidade } \\
\text { de Pearson }(\%) \ldots \ldots \ldots\end{array}$ & 68,7 & 140,1 & 86,2 & 85,3 & 93,0 \\
\hline
\end{tabular}


Vê-se de imediato que, por ordem crescente tanto de médias quanto de medianas do número de vermes, os tratamentos se dispõem na ordem B, E, D, C, e A; é também de consignar que, enquanto no lote testemunho todos os individuos apresentavam pelo menos um verme no tubo intestinal, respectivamente nos lotes $B$, E, D e C estavam livres da infestação oito, três, uma e duas aves. Além disso, como já foi assinalado ( $\mathrm{ROCHA}^{\prime}$ ), é grande a variabilidade na distribuição do número de vermes pelas aves, o que é pôstc $\mathrm{cm}$ evidência pelo coeficiente de Pearson.

No prosseguimento da análise, dadas as características da distribuição, tornou-se preferível utilizar um teste não paramétrico para julgar da diversidade dos lotes, quanto ao número de vermes presentes na luz intestinal.

Adotamos o processo de Kruskal \& Wallis (descrito por SIEGEL ${ }^{1 i}$ ), que consiste numa análise de variância onde, em vez dos dados originais, figuram os números de ordem a êles atribuidos na graduatória conjunta de todos os valores, calculando-se a estatística denominada $H$. No nosso caso, sem correção para os empates. foi achado para esta estatística o valor 20,42 que, comparado com o de $\mathrm{X}^{-}$, para quatro graus de liberdade e para o nivel de rejeição adotado, é significante, ultrapassando mesmo o valor crítico para o nivel de $1 \%$. Podemos rejeitar, portanto, a hipótese de que os lotes sejam todos iguais, no que toca ao número de vermes presentes no trato intestinal.

O teste de Mann \& Whitney (descrito por SIEGEL ${ }^{~}{ }^{i}$ ) permite esclarecer que a diversidade decorre, fundamentalmente, do número diminuto de vermes encontrados no lote $B$; com efeito, êste número difere significantemente dos registrados em qualquer dos mais tratamentos.

Era de esperar-se esta ação vermífuga da fenotiazina pois, como mostraram os bem documentados estudos de ROCHA $\because 2$, a droga quando ministrada durante a fase pós tecidual do ciclo do A. galli, apresenta certa atividade anti-helmíntica. 
Cumpre assinalar a disparidade entre os resultados dos tratamentos B e $\mathrm{E}$, que sugere dependência entre a ação da droga e os modos de administrá-la, diretamente no esôfago ou misturada à ração. A justificativa plausível para essa subordinação estaria na ocorrência da maior concentração momentânea do medicamento no intestino, quando adotada a primeira dessas formas de ministração.

Merece ainda menção a divergência dos resultados atinentes aos tratamentos $\mathrm{B}$ e $\mathrm{D}$, que põe em relêvo a influência da dosagem sôbre a intensidade da ação anti-helmíntica da droga.

As verificações ora assinaladas, embora valiosas, não dizem respeito ao objetivo desta tese, como foi exposto no início dêste capítulo. Dêste ponto de vista o que importa é a existência de aves com vermes, em todos os lotes, no término da primeira fase da experiência, deixando assegurada a possibilidade de contaminação dos vários solos pelos ovos que os parasitos pudessem próduzir. Desta forma, se a eventual ação profilática da fenotiazina corresse por conta unicamente, ou pelo menos essencialmente, da sua atividade vermífuga, seria de prever-se apenas grau diverso de contaminação do solo correspondente ao lote B quando confrontado com os restantes, que entre si não deveriam diferir significantemente.

É indispensável não perder de vista esta consideração, para que se possa interpretar devidamente os achados da fase final da experiência.

A fase preparatória, cuja descrição acabamos de oferecer, esquematiza-se da seguinte maneira: 
Chegada dos pintos

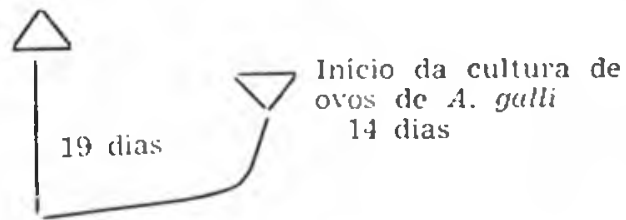

Infestaşào experimential

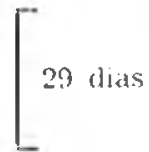

Presença de ovos nas lezos

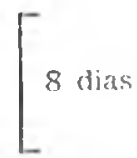

Alotação dos pintos
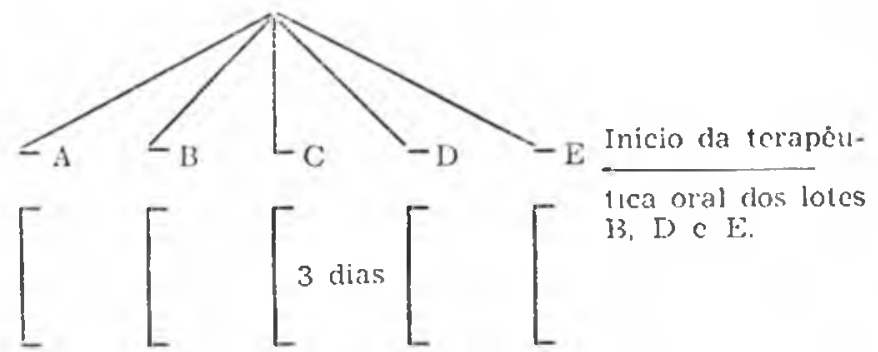

Transferencia paria os solos

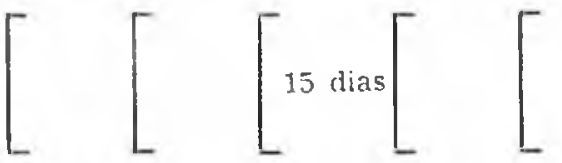

Sacrificio dos pintos c contagem do numero de vermes

\section{FASE FINAL}

Vimos que na fase preparatória procurou reproduzir-se, em experiência de tipo epidemiológico, as condições de contaminação de solos por animais infestados pelo A. galli; instituindo-se os diferentes tratamentos descritos, visou-se o estudo do efeito da fenotiazina sôbre tal contaminação.

Nesta fase final importava esclarecer se os vários solos, sujeitos aos diversos tratamentos, teriam adquirido igual capacidade de 
transmitir a infestação a animais suscetiveis, posteriormente com êles colocados em contacto. Para o planejamento da fase final bem menor era o número de problemas a solucionar, pois muitos já haviam sido resolvidos.

Novamente, para comodidade de exposição, dividiremos o assunto em tópicos.

1. Constituiçãc dos lotes - As aves do segundo grupo deveriam, fator essencial, na ocasião de as transportarmos para os solos, estar livres de infestação por A. galli. Com êsse objetivo, pintos de um dia de idade, da mesma procedência e com as mesmas características dos utilizados na fase preparatória, foram mantidos em lote único em criadeiras limpas e desinfetadas, providas de piso de tela metálica. Recebidos no dia em que o primeiro grupo de aves passou para os solos, coube-lhes a vez de ocupá-los um dia após a retirada dos primeiros; neste momento contavam. pois, dezoito dias, não tendo atingido, portanto, de acôrdo com HERRICK "' e ACKERT e col. " ", o perícdo da vida em que já se manifesta a chamada idade resistência; por outro lado, já era dispensável o aquecimento artificial dos pinteiros, capaz de interferir na viabilidade dos ovos.

Também entrou em consideração a questão do tamanho dos lotes. Evidentemente, quanto maior o número de unidades em cada lote, maior o poder dos testes para determinação da significância estatística de eventuais diferenças observadas entre os tratamentos. As limitações decorrentes da área disponível, entretanto, conduziram-nos a estabelecer em cêrca de sessenta o total de integrantes de cada lote, respeitado o critério de igualdade de tamanho dos diversos lotes. Atendendo a acidentais perdas antes da condução das aves para os solos, constituimos lote único, com 340 pintos de um dia de idade; com a morte de 26 animais durante o período citado, passamos a contar com 314 individuos. Desprezados quatro dêles, atribuimos os restantes, casualmente, aos cinco tratamentos, valendo-nos outra vez de quadrados latinos de lado cinco.

2. Colocação dos pintos nos solos - Tendo-se conhecimento (RIBEIRO NETTO "*) de que a ação inibidora da fenotiazina sôbre o desenvolvimento embrionário de ovos de A. galli. já pode ser decisiva decorridas 24 horas de contato dêstes com a droga, r'esolvemos estabelecer intervalo de um dia entre a retirada dos pintos 
do primeiro grupo e a mudança dos do segundo para os solos; a medida é particularmente justificada no caso dos lotes $\mathrm{C}$ e $\mathrm{D}$, por garantir a possibilidade de ação da fenotiazina sôbre ovos depositados no $15 .^{\circ}$ dia, por pintos da fase preliminar.

3. Permanência nos solos - Por ser de quinze dias, aproximadamente, o tempo previsivel para a maturação dos ovos de A. galli no solo, fixou-se êste prazo para a permanência das aves nos pinteiros.

Em duas oportunidade, durante tal período, sulcamos os solos pouco profundamente com um ancinho flambado antes de cada operação, a fim de trazer à superfície ovos porventura enterrados pelo superposição de excretos e pelo pisotear constante das aves, que tornava o solo muito compacto.

Quando da estada nos solos, morreram vinte e sete pintos, assim distribuidos: lote $\mathrm{A}$, onze; lote $\mathrm{B}$, cinco; lote $\mathrm{C}$, dez e lote $\mathrm{D}$, um; como se vê não ocorreram mortes entre os pintos do lote $\mathrm{E}$.

Muito embora não constasse do planejamento desta tese o exame dêste aspecto, chamou-nos a atenção a mortalidade desigual verificada nos diferentes lotes. Resolvemos, porisso, testar a hipótese de nulidade segundo a qual a mortalidade nos vários lotes seria a mesma. A hipótese alternativa era a de que a mortalidade nos diversos lotes fôsse diferente. Adotamos como nível de rejeição o valor 0,05 . $\mathrm{Da}$ análise dos dados resultou um valor de $\mathrm{X}^{2}$ igual a 20,643 que, comparado com o valor crítico desta estatística para quatro graus de liberdade e para o nível de rejeição adotado, é significante, ultrapassando mesmo o valor crítico para 0,01. Diante dêste resultado, rejeitamos a hipótese de nulidade, aceitando a alternativa de que a mortalidade nos vários lotes é diferente. Face a esta verificação, deu-se prosseguimento à análise recorrendo-se à decomposição aditiva do $\mathrm{X}^{*}$, nos moldes preconizados por COCHRAN ${ }^{21}$, reunindo, de um lado, os lotes $\mathrm{A}$ e C que tinham em comum o fato de haverem permanecido sôbre solos anteriormente habitados por aves infestadas pelo A. galli e não tratadas por via oral com fenotlazina; de outro lado, grupamos os lotes B, D e E que haviam permanecido sôbre solos anteriormente habitados por aves parasitadas e tratadas por via oral com fenotiazina. Os dados relativos à mortalidade verificada nestes dois grupos encontram-se no quadro III e os resultados da análise, no quadro IV. 
QUADRO III

Mortalidade observada nos grupos AC e BDE

\begin{tabular}{|c|c|c|c|c|}
\hline Grupos & Mortos & Sobreviventes & Total & Proporção de mortos \\
\hline $\mathrm{AC}$ & 21 & 103 & 124 & $21 / 124=0,169$ \\
\hline BDE & 6 & 180 & 186 & $6 / 186=0,032$ \\
\hline Total ........... & 27 & 283 & 310 & $27 / 310=0,087$ \\
\hline
\end{tabular}

QUADRO IV

Decomposição aditiva de $\mathrm{X} 2$ para a mortalidade entre e dentro dos grupos $\mathrm{AC}$ e BDE

\begin{tabular}{l|c|c|c}
\hline \multicolumn{1}{c|}{ Fonte de variaçăio } & $\begin{array}{c}\text { Graus de } \\
\text { liberdáde }\end{array}$ & Variação & Variância \\
\hline \hline Entre grupos ........ & 1 & 1,397 & 17.683 \\
Dentro do grupo AC ... & 1 & 0,226 & 2,858 \\
Dentro do grupo BDE ... & 2 & 0,008 & 0,102 \\
\hline Total .............. & 4 & 1,631 & 20.643 \\
\hline
\end{tabular}

Vê-se, pois, que a mortalidade difere significantemente de um grupo para outro, sendo maior para o primciro. Verifica-se ainda a inexistência de diferenças significantes dentro de cada um dos grupos.

É provável que a maior mortalidade observada nos lotes $\mathrm{A}$ e $\mathrm{C}$ tenha ocorrido por conta de uma ação patogênica do A. galli, pois, como veremos, foram justamente êstes lotes os que se mostraram mais parasitados. Esta ação patogênica do parasito já tem sido, aliás, apontada por outros pesquisadores como Ackert (citado por REIS \& NOBREGA ${ }^{22}$ ) e HERRICK ${ }^{23}$.

4. Sacrifício dos pintos e contagem do número de vermes As aves remanescentes foram, passados os quinze dias, retiradas dos solos e transferidas para pinteiros com piso de tela metálica, onde permaneceram por mais vinte e cinco dias, tempo necessário para assegurar o término da fase tecidual do ciclo evolutivo do $\mathbf{A}$. galli, que segundo TUGWELL \& ACKERT ${ }^{1: 3}$ e ROCHA ", ocorre entre o 18. ${ }^{\circ}$ e $26^{\circ}$ dias a partir do da infestação. Esgotado êste prazo, sacrificamos todos os pintos e contamos os vermes existentes na luz intestinal; os resultados figuram no quadro $\mathrm{V}$. 
Rev. Fac. Med. Vet. S. Paulo - Vol. 6, fasc. 3, 1959

QUADRO V

Ninvero de vermes encontrados na luz intestinal de cada um dos pintos, em cada um los lotes

\begin{tabular}{|c|c|c|c|c|c|}
\hline & \multicolumn{5}{|c|}{ LOTES } \\
\hline & $A$ & $\mathbf{B}$ & C & $\mathrm{D}$ & $\mathbf{E}$ \\
\hline & $\begin{array}{r}1 \\
1 \\
1 \\
1 \\
2 \\
2 \\
2 \\
2 \\
2 \\
2 \\
3 \\
3 \\
3 \\
3 \\
3 \\
4 \\
4 \\
4 \\
4 \\
5 \\
7 \\
7 \\
8 \\
8 \\
8 \\
8 \\
9 \\
9 \\
9 \\
10 \\
12 \\
12 \\
12 \\
13 \\
13 \\
15 \\
15 \\
18 \\
18 \\
19 \\
19 \\
21 \\
21 \\
23 \\
26 \\
28 \\
40 \\
49 \\
60 \\
65 \\
75\end{array}$ & $\begin{array}{l}0 \\
0 \\
0 \\
0 \\
0 \\
0 \\
0 \\
0 \\
0 \\
0 \\
0 \\
0 \\
0 \\
0 \\
0 \\
0 \\
0 \\
0 \\
0 \\
0 \\
0 \\
0 \\
0 \\
0 \\
0 \\
0 \\
0 \\
0 \\
0 \\
0 \\
0 \\
0 \\
0 \\
0 \\
0 \\
0 \\
0 \\
0 \\
0 \\
0 \\
0 \\
0 \\
0 \\
0 \\
0 \\
0 \\
0 \\
0 \\
0 \\
0 \\
0 \\
0 \\
0 \\
0 \\
0 \\
1 \\
3\end{array}$ & $\begin{array}{r}0 \\
0 \\
0 \\
0 \\
0 \\
0 \\
0 \\
0 \\
0 \\
1 \\
1 \\
1 \\
1 \\
1 \\
1 \\
1 \\
1 \\
1 \\
1 \\
2 \\
2 \\
2 \\
2 \\
2 \\
2 \\
2 \\
3 \\
3 \\
3 \\
3 \\
3 \\
3 \\
3 \\
4 \\
4 \\
4 \\
4 \\
4 \\
4 \\
4 \\
4 \\
4 \\
4 \\
5 \\
5 \\
5 \\
4 \\
10 \\
12 \\
12 \\
12 \\
21\end{array}$ & $\begin{array}{l}0 \\
0 \\
0 \\
0 \\
0 \\
0 \\
0 \\
0 \\
0 \\
0 \\
0 \\
0 \\
0 \\
0 \\
0 \\
0 \\
0 \\
0 \\
0 \\
0 \\
0 \\
0 \\
0 \\
0 \\
0\end{array}$ & $\begin{array}{l}0 \\
0 \\
0 \\
0 \\
0 \\
0 \\
0 \\
0 \\
0 \\
0 \\
0 \\
0 \\
0 \\
0 \\
0 \\
0 \\
0 \\
0 \\
0 \\
0 \\
0 \\
0 \\
0 \\
0 \\
0 \\
0 \\
0 \\
0 \\
0 \\
0 \\
0 \\
0 \\
0 \\
0 \\
0 \\
0 \\
0 \\
0 \\
0 \\
0 \\
0 \\
0 \\
0 \\
0 \\
0 \\
0 \\
0 \\
0 \\
0 \\
0 \\
0 \\
0 \\
0 \\
0 \\
0 \\
0 \\
0 \\
0 \\
0 \\
0 \\
0 \\
0 \\
0 \\
0 \\
1\end{array}$ \\
\hline rotal $\ldots \ldots \ldots \ldots \ldots \ldots \ldots$ & 709 & 4 & 173 & 2 & 1 \\
\hline N.o médlo $\ldots \ldots \ldots \ldots \ldots$ & 13,90 & 0,07 & 3,33 & 0,03 & 0,02 \\
\hline N.e mediano $\ldots \ldots \ldots \ldots \ldots$ & 7 & 0 & 2,5 & 0 & 0 \\
\hline N.O de plntos sem vermes .. & 0 & 55 & 9 & 59 & 61 \\
\hline Desvlo padråo $\ldots \ldots \ldots \ldots$ & 16,5 & & 3,8 & & \\
\hline $\begin{array}{l}\text { Coeficlente de variabilldade } \\
\text { de Pearson }(\%) \text {......... }\end{array}$ & 118,8 & & 115,4 & & \\
\hline
\end{tabular}


A fase final, cuja descrição acabamos de oferecer, esquematiza-se da seguinte maneira:

Chegada do II grupo de pintos

(por ocasião da colocação do I grupo nos solos)

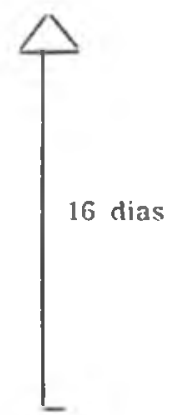

Alotação dos pintos

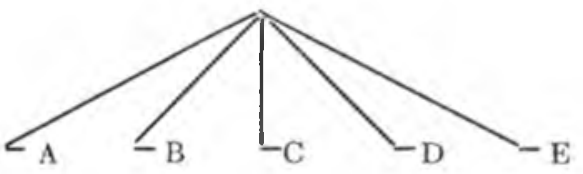

Transferencia para os solos

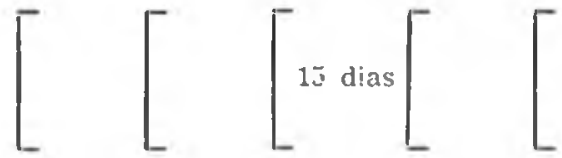

Transferēncia para pisos de tela

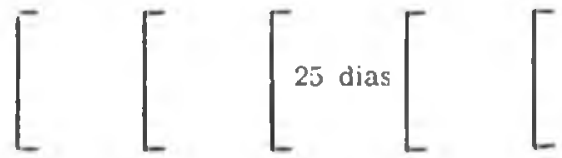

Sacrificio dos pintos e contagem do número de vermes

5. Análise dos resultados e discussão - Alẻm dos resultados das contagens dos vermes presentes na luz intestinal dos pintos, figuram no quadro $V$, para cada um dos lotes, os valores referentes à média, à mediana, ao número de pintos sem vermes, ao desvio padrão e ao coeficiente de variabilidade de Pearson.

Esses resultados obtidos para o número de vermes nos cinco lotes são de tal natureza que tornam dispensável qualquer análise 
estatística para pôr em relêvo a significância da diversidade entre tratamentos. Também é prescindível qualquer elahoração para mostrar que os lotes B (fenotiazina granulada, por via oral, administrada com auxílio de sonda), D (fenotiazina em pó, adicionada ao solo, e granulada administrada per os) e E (Fenotiazina em pó, por via oral, misturada à ração), não diferem significantemente uns dos outros, mas diferem significantemente tanto do lote A (testemunho) quanto do lote $\mathbf{C}$ (fenotiazina em pó, adicionada ao solo).

A única diferença que permitiria alguma dúvida quanto à sua significância era a verificada entre os tratamentos C e A; entretanto, quer recorrendo-se ao teste de Mann \& Whitney (descrito por SIEGEL ${ }^{1 \overline{ }}$ ), quer ao da diferença entre as percentagens de negatividade, evidencia-se, relativamente ao tratamento $\mathrm{C}$, número de vermes significantemente menor do que no testemunho.

Diante de tais resultados, fomos levados a rejeitar a hipótese de nulidade, inicialmente posta, aceitando a alternativa de que a fenotiazina exerce alguma ação inibitória sôbre a postura ou o desenvolvimento embrionário de ovos de A. galli. ou sôbre ambos, ação esta utilizável como medida profilática.

Efetivamente, os dados obtidos demonstram, de maneira incontestável, que a administração continuada de fenotiazina, por via oral, a pintos parasitados pelo A. galli, é capaz de proteger da infestação outros pintos colocados sôbre o solo onde permaneceram os primeiros; o mesmo acontece, embora com eficiência muito menor, quando se lança a droga ao piso de terra.

Cabe-nos aventar explicações para a menor eficácia da fenotiazina quando adicionada ao solo, em comparação com a ministrada por via oral. Neste último caso, como foi demonstrado (ROCHA ${ }^{2}$ ) a droga exerce duas ações: inibe a ovoposição e impede o desenvolvimento embrionário dos ovos de A. galli. Distribuída pelo solo a fenotiazina somente pode desempenhar a segunda das ações mencionadas e, ainda assim, com menores probabilidades de edificência, pela dificuldade de ocorrer contacto perfeito da subsância com ovos do parasito contidos na massa fecal. Não se pode, igualmente, excluir a hipótese da inativação da fenotiazina no solo; todavia, se tal inativação não ocorre e, posteriormente, a desintegração do bolo fecal viesse a facilitar o contacto da droga com os ovos, êstes já poderiam ter atingido estádio de desenvolvimento 
no qual, segundo ROCHA * e RIBEIRO NETTO ", não mais se revelariam sensiveis ao medicamento.

A ausência de diversidade nos resultados encontrados para os lotes B, D e E é de capital importância, pôsto que, em todos êles, os animais receberam fenotiazina por via oral; ora, enquanto nos grupos B e D fêz-se a introdução direta da fenotiazina no inglúvio, técnica incluida no planejamento por assegurar maior rigor de dosagem, já no caso do lote $\mathrm{E}$ realizou-se a simples adição da droga à ração, o que, do ponto de vista prático, tem grande significado.

$\mathrm{Na}$ verdade a mistura de um medicamento à ração representa meio fácil de ministração, atributo de grande valia para a difusão de medidas profiláticas.

Tem-se em mente que a ascaridiase das galinhas constitui, na opinião de vários AA. ${ }^{24}{ }^{25 .}{ }^{26}$, uma das helmintiases mais freqüentes destas aves, com larga participação na mortalidade ${ }^{2 *}$. $*$, a evidência obtida quanto ao tipo de profilaxia medicamentosa que acabamos de discutir, abre novas e promissoras perspectivas para a solução de problema de real magnitude.

Já tendo sido demonstrado ( $\mathrm{ROCHA}$ ) que a fenotiazina pode agir, in vitro, também sôbre ovos de outros nematóides, fica aberto um largo campo para investigações que visem a possibilidade de extensão desta mesma forma de profilaxia a outras parasitoses e em outras espécies animais.

\section{CONCLUSŌES}

Os resultados da experimentacão, analisados e discutidos, conduziram-nos às seguintes conclusões:

1) O número de vermes encontrado em intestinos de pintos suscetíveis que permaneceram sôbre solos que tinham sido habitados por aves parasitadas pelo A. galli e tratadas de maneira contínua com fenotiazina, por via oral, é significantemente menor do que o observado em intestinos de pintos suscetiveis que permaneceram sôbre solos que haviam sido habitados por aves infestadas $e$ não submetidas à ação da droga.

2) O número de vermes encontrado em intestinos de pintos suscetíveis que permaneceram sĉbre solos anteriormente tratados pela fenotiazina e habitados por aves parasitadas pelo A. galli, é significantemente menor do que o observado em intestinos de pin- 
tos suscetiveis que permaneceram sôbre solos que não receberam a droga e foram habitados por animais infestados.

3) O número de vermes encontrado em intestinos de pintos suscetíveis que permaneceram sôbre solos que haviam sido habitados por aves parasitadas pelo $\mathbf{A}$. galli e tratadas de maneira contínua com fenotiazina, por via oral, é significantemente menor do que o observado em intestinos de pintos suscetíveis que permaneceram sôbre solos que receberam a droga e foram habitados por aves infestadas.

4) O número de vermes encontrado em intestinos de pintos suscetiveis que permaneceram sôbre solos que haviam sido habitados por aves parasitadas pelo A. galli e tratadas de modo contínuo com fenotiazina, por via oral, administrada através de sonda, não difere significantemente do observado em pintos suscetíveis que permaneceram sôbre solos que haviam sido habitados por animais infestados que receberam, também de modo contínuo, na ração, a mesma droga.

5) A mortalidade observada em pintos suscetiveis que permaneceram sôbre solos que haviam sido habitados por aves parasitadas pelo A. galli e tratadas continuamente com fenotiazina, por via oral, é significantemente menor do que a mortalidade observada em pintos suscetiveis que permaneceram sôbre solos que haviam sido habitados por aves infestadas e que não receberam fenotiazina por via oral; a forma de ministrar a fenotiazina, por sonda ou de mistura à ração, não determina diferença significante na mortalidade; quando a droga não é ministrada por via oral, o fato de ser a mesma colocada ou não no solo também não condiciona diferança significante na mortalidade.

6) As conclusões anteriores fornecem um conjunto de informações suficiente para que se possa considerar aconselhável a ministração continuada de fenotiazina de mistura com a ração, às aves parasitadas pelo A. galli, como medida de profilaxia desta ascaridiase.

\section{SUMMARY}

In the experimental epidemiological study on the use of phenothiazine in the profilaxis of chicken ascariasis the author was able to conclude that:

1 - The number of worms found in the intestines of susceptible chicken that lived on soil previously inhabited by fowls in- 
fected with A. galli and treated continuosly with phenothiazine by oral route, is significantly lower than that observed in the intestines of susceptible chicken that lived on soil previously inhabited by fowls infected and not treated.

2 - The number of worms found in the intestines of susceptible chicken that lived on soil previously treated with phenothiazine and inhabited by birds infected with $\boldsymbol{\Lambda}$. galli, is significantly lower than that observed in the intestines of susceptible chicken that stood on soil not treated with the drug and inhabited by infected animals.

3 - The number of worms found in the intestines of chicken that stood on soil inhabited by birds infected with $\boldsymbol{\Lambda}$. galli and treated continuously with phenothiazine, by oral route, is significantly lower than that observed in the intestines of susceptible chicken that stood on soil treated with the drug and inhabited by infected animals.

4 - The number of worms found in the intestines of susceptible chicken that stood on soil that had been inhabited by birds infected by $\mathbf{A}$. galli and treated continuously with phenothiazine, by oral route administered with stomach tube, does not differ significantly from that observed in susceptible chicken that lived on soil previously inhabited by infected animals that received continuously the same drug in their rations.

5 - The mortality observed in susceptible chicken that stood on soil previously inhabited by chicken infected with $\mathbf{A}$. galli and treated continuously with phenothiazine, by oral route, is significantly lower than the mortality observed in suscaptible chicken that lived on soil that had been inhabited by infected birds that did not received phenothiazine by oral route; the manner by which phenothiazine was administered, either by tube or mixed in the ration, does not determine a significant difference in the mortality; when the drug is not given orally, the spreading or not of it on soil does not cause a significant difference in mortality as well.

6 - The foregoing outcomes provide a set of information to recommend continuous administration of phenothiazine mixed in ration, to infected chicken with $\mathbf{A}$. galli, as a profilaxis measure. 


\section{BIBLIOGRAFIA}

1. Roch4, U. F. - 1955 - Ensaio crítico do método de Ackert, como meio de avaliação da atividade anti-helmíntica da tiodifenilamina (fenotiazina) contra Ascaridia galli (Schrank, 1788) em pintos. Tese Fac. Med. Vet., S. Paulo (multiliht)

2. Rochs, U. F. - 1957 - Novas investigações sôbre o modo de ação da fenotiazina. Contribuição para o estudo do efeito da droga sôbre a Ascaridia galli (Schrank, 1788), em várias fases do seu ciclo evolutivo; ensaio preliminar referente à ação da fenotiazina sôbre ovos de outros nematóides. Tese Fac. Med. Vet., S. Paulo (rotaprint)

3. Harwood, P. D. - Jerstad, A. C. - Swanson, L. E. - 1938 The efficacy of phenothiazine for the removal of ascarids and nodular worms frcm swine. J. Parasit., 24, Suppl.: 16

4. Todd, A. C. - Hansen, M. F. - Kelley, G. W. - Wyant, Z. N. 1949 - Continuous phenothiazine therapy for horses: I. Effect on the worm paraste. Vet. Med., 44 (10):411-4

5. Hansen, M. F. - Tod, A. C. - Kelley, G. W. - 1949 - Continuous phenothizzine therapy for horses: II. Hematological studies with a note on postmortem findings. Vet. Med., 44 (11): 461-4

6. Todd, A. C. - Hansen, M. F. - Wyant, Z. N. - Crowds, D. H. Cawern, M. J. - 1950 - Continuous phenothiazine therapy for horses: III. The second year of treatment. Vet. Med., 45 (11):429-34

7. TODD, A. C. - 1952 - Continuous phenothiazine therapy for horses: IV. The third year of treatment. Vet. Med., 47 (1): 25-6

8. Drudge, J. H. - Wyant, Z. N. - Elam, G. W. - 1953 - Continuous phenothiazine therapy for horses. Vet. Med., $48(8): 306-10$

9. Drudge, J. H. - Wyant, Z. N. - Elam, G. W. - 1955 - Continuous phenothiazine therapy for horses: II. A texonomic study following four years of treatment. Amer. J. Vet. Res., 16 (58):18-21

10. RIEDEL, B. B. - 1947 - New technique on culturing and feeding ascarid eggs. Trans. Amer. Micr. Soc., 66(4):396-7

11. HANSEN, M. F. - Olson, L. J. - ACKert, J. E. - 1954 - Improved techniques for culturing and administering ascarid eggs to experimental chicks. Exp. Parasit., 3 (5) : 464-73

12. Pessoa, S. B. - 1954 - Parasitologia médica. 4. ${ }^{\text {a }}$ ed. Rio de J., Livraria Editora Guanabara

13. Tugwell, R. L. - Acrert, J. E. - 1952 - On the tissue phase of the life cycle of the fowl nematode Ascaridia galli (Schrank). J. Parasit., 38 (4) : 277-88 
14. EwING, W. R. - 1951 - Poultry nutrition. 4th ed. New York, American Book-Knickerbocker Press

15. Fischer, R. A. - Yates, F. - 1949 - Tablas estadisticas. 3. ${ }^{\mathrm{a}}$ ed., Madrid, Aguillar

16. Ackert, J. E. - Nolf, L. O. - 1929 - New technique for collecting intestinal roundworms. Science, 70 (1813):310-11

17. Siegel, S. - 1956 - Nonparametric Statistics for the mehavioral ciences. New York, Mc Graw-Hill Book Company, Inc.

18. Herrick, C. A. - 1926 - Studies on the resistance of the chicken to the nematode Ascaridia perspicillum. Amer, J. Hyg., 6 (1): 153-72

19. Ackert, J. E. - PorTer, D. A. - BeAch, T. D. - 1935 - Age resistance of the chicken to the nematode Ascaridia lineata (Schneider). J. Parasit., 21 (3) : 205-13

20. Ribeiro NetTo, A. - 1958 - Nota sôbre a inibição, in vitro, pela fenotiazina, do desenvolvimento embrionário de ovos de $A$. galli. (Schrank, 1788) . Rev, Fac. Med. Vet., S. Paulo, 6 (2): 181

21. Cochran, W. G. - 1954 - Some methods for strenghtening the common $\mathrm{X}^{2}$ test. Biometrics, 10:417-51

22. ReIs, J. - Nobrega, P. - 1956 - Tratado de doenças das aves. 2. a ed. V. 4. S. Paulo, Edições Melhoramentos.p. 65

23. Herrick, C. A. - 1923 - Some effects of Ascaridia perspicillum (Rud.). Anat. Res., 26 (5) :359

24. Moraes, R. G. - 1938 - Notas sôbre a incidência de nematodeos em Gallus domesticus no Estado de Minas Gerais. Campo, Rio de J., $9(98): 48$

25. Tod, A. C. - 1947 - Helminth infections in chickens from Tennessee. Poult. Sci., 26:469-74

26. Ackert, J. E. - 1923 - On the life-history of the fowl nematode Ascaridia perspicillum (Rud.). Anat. Rec, 26 (5):356 